\title{
Birth defects and congenital health risks in children conceived through assisted reproduction technology (ART): a meeting report
}

\author{
ESHRE Capri Workshop Group
}

Received: 19 March 2014 / Accepted: 8 May 2014 / Published online: 29 May 2014

(C) Springer Science+Business Media New York 2014

\begin{abstract}
Purpose Assisted Reproduction Treatment (ART) is here to stay. This review addresses the parental background of birth defects, before, during and after conception and focuses both
\end{abstract}

ESHRE Capri Workshop Group A meeting was organized by ESHRE [September 1-2, 2013] to discuss the above subjects. The contributors included: D. F. Albertini (Department of Physiology, Kansas University Medical Center, Kansas City, Kansas, USA), J.L.H. Evers (Dept. Obstet. Gynaecol., Maastricht University Medical Centre, Maastricht, The Netherlands), J.P.M. Geraedts (Department of Genetics and Cell Biology, University Maastricht, The Netherlands), L. Gianaroli (SISMER, Reproductive Medicine Unit, Bologna, Italy), R. Sharpe (MRC Centre for Reproductive Health, The Queen's Medical Research Institute, University of Edinburgh, UK), K. D. Sinclair (School of Biosciences, University of Nottingham, Sutton Bonington Campus, Leicestershire, UK), A. Sunde (Dept of Ob. and Gyn. University of Trondheim, Norway), A. Van Steirteghem (Centre for Reproductive Medicine, Universitair Ziekenhuis Vrije Universiteit Brussel, Belgium). The discussants included: D.T. Baird (Centre for Reproductive Biology, University of Edinburgh, UK), P.G. Crosignani (Scientific Direction, IRCCS Ca' Granda Foundation, Maggiore Policlinico Hospital, Milano, Italy), P. Devroey (Centre for Reproductive Medicine, Universitair Ziekenhuis Vrije Universiteit Brussel, Belgium), K. Diedrich (Klinik für Frauenheilkunde und Geburtshilfe, Universitätsklinikum Schleswig-Holstein, Campus Lübeck, Germany), B.C.J.M. Fauser (Department of Reproductive Medicine and Gynaecology, University Medical Center, Utrecht, The Netherlands), L. Fraser (Reproduction and Rhythms Group, School of Biomedical and Health Sciences, Kings College London, UK), J.S. Tapanainen (University of Helsinki, Department of Obstetrics and Gynaecology, Helsinki University Central Hospital, Helsinki, and University of Oulu, Department of Obstetrics and Gynaecology, Oulu University Hospital, Oulu and Medical Research Center Oulu, Oulu, Finland), B. Tarlatzis (Unit for Human Reproduction, 1st Dept of OB/ GYN, Medical School, Aristotle University of Thessaloniki, Thessaloniki, Greece), A. Veiga (Director CMRB Barcelona Stem Cell Bank, Barcelona, Spain). The report was prepared by P.G. Crosignani and J.L.H. Evers.

Capsule Remaining mindful of the growing body of evidence showing that during gamete production, genetic and epigenetic changes influence offspring health, serves to reinforce the need to continue to monitor ART children.

ESHRE Capri Workshop Group $(\bowtie)$

Scientific Direction, IRCCS Ca' Granda Foundation Maggiore

Policlinico Hospital, Via M. Fanti, 6, 20122 Milan, Italy

e-mail: piergiorgio.crosignani@unimi.it on the underlying subfertility and on the question whether ART as a treatment is an additional contributing factor.

Methods Searches were performed in Medline and other databases. Summaries were discussed in a Delphi panel set-up by the European Society of Human Reproduction and Embryology (ESHRE).

Results Several birth defects and adult diseases arise during the earliest stages of ovarian development and oocyte differentiation: this is the case of cleft palate disorders in offspring from female rat exposed to Dioxin during fetal life or the polycystic ovary diseases in female offspring (primates) exposed to elevated androgen concentration during fetal life. Human oocytes and embryos often fail to stop the propagation of aneuploid cells but maintain their ability to repair DNA damages including those introduced by the fertilizing sperm. There is a $29 \%$ increased risk of birth defects in the newborns spontaneously conceived by subfertile couples and the risk is further increased (34\%) when conception is achieved by treating infertlity with ART (Danish IVF Registry). Periconceptional conditions are critical for ART babies: their birth weight is in general smaller (Norvegian Registry) but a more prolonged culture time doubled the number of large babies (Finnish Registry). Conclusion The long-term developmental effects of ART on child and subsequent health as an adult remains a subject worthy of futher monitoring and investigation.

Keywords Birth defects $\cdot$ Malformations $\cdot$ Congenital health risks $\cdot$ Genetic diseases $\cdot$ Epigenetic defects

\section{Introduction}

Ex ovo omnia: "everything comes from the egg". William Harvey published this visionary statement on human reproduction in the 17th century [1]. This review addresses the 
parental background of birth defects, before, during and after conception and focuses both on the underlying subfertility and on the question whether ART as a treatment is an additional contributing factor. We now have compelling evidence that also the origins of birth defects and perhaps other childhood and adult diseases can arise during the earliest stages of gonad development and gamete differentiation and are almost exclusive to the egg. Bridging the gap between the process of oogenesis or spermatogenesis on the one hand, and offspring fitness on the other is a challenge to basic and clinical scientists alike. Advances in contemporary biomedical research and reproductive medicine are now offering promising and relevant insights that are likely to impact patient care as it relates to ensuring both the short- and long-term health of future generations.

We would all agree that IVF was a very impotant advance in the treatment of infertility. Many thousands of couples who otherwise would have remained childless have had the joy of parenthood. Equally significant the ability to study human eggs and sperm in vitro has given us an understanding of the processes of fertilization and early embryogenesis which 30 years ago could only be studied in other species. Of particular relevance the causes of the very high incidence of abnormal embryos found in women can be studied in detail.

\section{Methods}

Searches were performed in Medline and other relevant databases by individual participants in the workshop. Selection criteria included high quality studies and studies pertinent to clinical reproductive medicine. Each subject summary was presented to the European Society of Human Reproduction and Embryology (ESHRE) Workshop Group in a modified Delphi panel set-up where omissions were identified and disagreements were resolved by ample discussion. A structured communication technique was followed in a systematic, interactive method between the panel of experts. After each presentation, one or more discussants provided a summary and critical appraisal of the experts' findings and conclusions which then was subject to a group evaluation. The input of individual panel members was weighed as were the reasons they provided for their contributions. Thus, experts were encouraged to adapt or modify their conclusions in light of the validity of the input by other members of the ESHRE workshop panel. The idea was that during this process the range of the 'soft' conclusions-inherently broad in this explorative type of (para) clinical research-will decrease and the group will converge towards a focused conclusion. Following the meeting, consensus was reached after circulation and recirculation of the manuscript among the expert participants.

\section{Ex Ovo omnia}

Historically, two guiding principles derived from classical embryology and reproductive physiology are paving the way towards deepening our understanding of the relationship between the developmental origins of oocyte and embryo quality, embedded within the context of oogenesis and offspring health.

The first of these is the notion that "embryogenesis presupposes oogenesis" enunciated in the early 20th century in the classical works of E.B. Wilson [2] and P. Raven [3]. Such landmark studies emphasized the essential and formative association between maternal health, oogenesis, and the ability of the early embryo to sustain and direct development of a new organism as a result of information encoded within the ovum. Some 40 years later, Professor C. Thibault in his Hammond Memorial Lecture entitled "Are follicular maturation and oocyte maturation independent processes?", furthered the realization that oocyte quality in mammals was directly coupled to events taking place within the ovarian follicle [4]. Now it is widely accepted that maternal health and the attendant influences of age, lifestyle, environmental exposures and medical interventions, such as controlled ovarian hyperstimulation impact oocyte quality and offspring health and contribute to the origins of birth defects and developmental deficiencies manifest at birth or later stages of life [5-8].

What emerges from the conceptualization of a developmental continuum is the likelihood and prospect of sensitive windows during which the genetic, epigenetic, and genomic integrity of the conceptus could be affected in a manner consistent with the ontogeny of birth defects or other compromising health conditions [9].

One example of this comes from studies in which pregnant rats were exposed to dioxin, an environmental toxicant, during the latter half of gestation as gonadogenesis was occurring [6]. The impact of environmental exposures during gestation on the subsequent DNA repair and chromatin remodeling capacities of the oocyte and preimplantation embryo was demonstrated in the context of cleft palate disorders in offspring from mothers exposed during fetal life $[6,10]$. This implies that disturbances in the earliest stages of chromatin disposition during gonadogenesis present with specific defects in embryogenesis (cell cycle timing, heterochromatization, compaction, cell allocation) that manifest themselves as craniofacial defects in the next generation offspring.

A second striking example derives from the work of Abbott and colleagues [11]. Their studies in primates trace the impact of early gestational exposure to androgens on the incidence of polycystic ovary disease in female offspring. This work reinforces and emphasizes the importance of "sensitive windows" of exposure during fetal ovarian development that somehow 
compromise the ability of the oocyte to initiate and sustain the genetic and epigenetic determinants of offspring health. The dramatic effect of elevated androgens on polycystic ovary disease in female offspring is a particularly telling example of maternal health status operating through the female germ line.

How might perturbations in metabolism in the fetal gonad be translated into a health risk for offspring? There are no answers to such an overarching question but one glimpse into this quandary may be based in the integration between follicular and oocyte maturation [12]. Structural and physiological studies have now confirmed that a network of cellular interactions mediate critical aspects of oocyte metabolism that have a direct and immediate consequence of postfertilization development of the conceptus [10, 13, 14] (Fig. 1). How early in oogenesis are these interactions established and for how long are they maintained during the protracted development of both the follicle and its enclosed oocyte? The recent review from Ménézo and colleagues on folate metabolism [9] coupled with the demonstration of the positive effect of pre-conceptional folate supplements on the incidence of autism in offspring [8] imply a potential relationship between follicular folate metabolism and embryo quality. The growing realization that first and second generation transmission of traits to offspring observed in animal models requires critical evaluation in the context of human health, should be tempered by recognition of the caveat that animal models can sometimes raise concerns that are not fully warranted in humans [10].

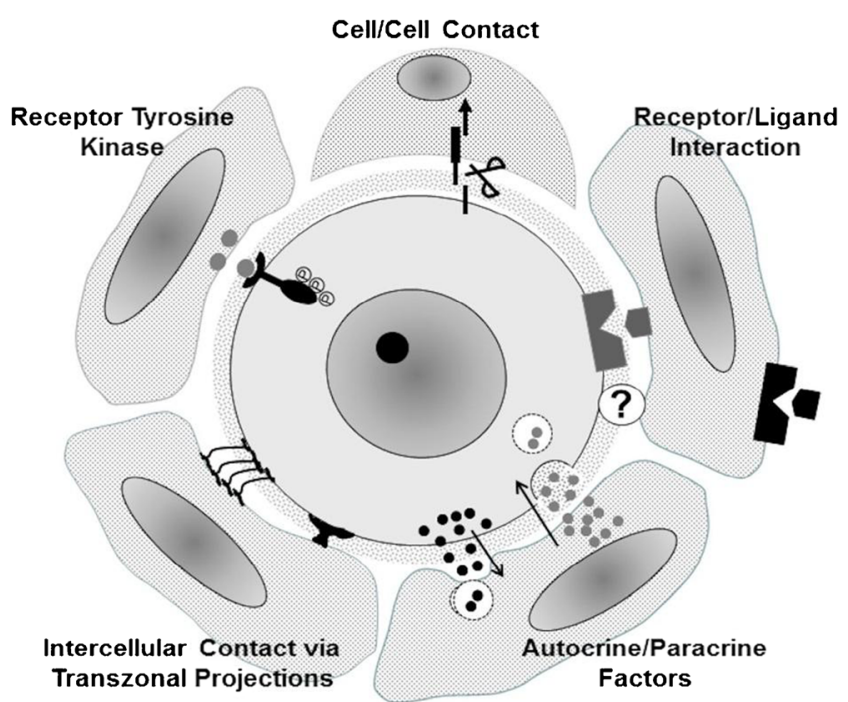

Fig. 1 Currently recognized forms of intercellular interactions between mammalian oocytes and their enveloping granulosa cells. Types of signaling interactions depicted are believed to operate at different stages of follicle development to mediate coordination of oogenesis and folliculogenesis and ensure that somatic cells provide metabolic support to the oocyte. Adapted from McGinnis et al. [14]

\section{Chromosomal disorders and DNA repair mechanisms in human eggs}

One of the most distinguishing features of human reproduction is the prevalence of age-related aneuploidy in the female germ line and preimplantation embryo. Why the human conceptus exhibits such a striking disposition towards genetic instability has puzzled physicians and scientists alike since it was first recognized over 60 years ago $[15,16]$. But with advances in ART technology, and the adoption of molecular genetics for high resolution characterization of chromosomal disorders, the purview of this problem has shifted from one of documentation to the question of "why"? Since the production of aneuploid gametes or embryos as a result of numerical or structural alterations in chromosomes is generally viewed as a source of spontaneous abortion or potential birth defects, the negative connotation of failed reproduction is an apt and widely appreciated example of poor outcomes, just as it has been in the field of cancer biology [16]. But in reproductive medicine, as in other disciplines, the definition of genetic instability has been broadened to account for the discovery of other forms of genomic modifications that are equally important, if not more so, in the generation of congenital diseases or disorders that emerge at later stages of life.

From the perspective of the cell cycle, it has been appreciated for over two decades now that cells display a remarkable ability to recognise errors in DNA replication or chromosome segregation. The concept and demonstration of cell cycle checkpoints has provided an important experimental platform upon which the molecular and biochemical underpinnings are based that allow for the detection and elimination of cells bearing genetic mistakes of one kind or another. By executing checkpoint control at specific stages of the cell cycle, normal tissues avoid accumulating genetic errors that predispose cells or tissues to diseases such as cancer [17]. Robust checkpoints operate during mammalian spermatogenesis to eliminate most chromosomally imbalanced sperm [16]. Surprisingly, human oocytes and embryos, especially those derived from older individuals, fail to implement discriminating cell cycle checkpoints [18] and as a result allow for the propagation of aneuploid cells with both potential beneficial and deleterious effects to the somatic organism [19].

Based on the above, an acceptable but by no means complete response to the question of "Why All The Aneuploidies?" appears founded in the lack of cell cycle checkpoint control in human oocytes and embryos consistent with recent work suggesting, at a mechanistic level, that the oocytes of older women fail to express sufficient quantities of proteins involved in chromosomal integrity or important cell cycle regulators [20].

A more pressing concern as to the origins and consequences of birth defects is to what extent our classical views of genetic integrity have fallen short of recognizing contemporary notions of genomic integrity (Fig. 2). 
Fig. 2 Schematic depicting impact of aging, lifestyle factors (such as diet, smoking), and environmental exposure on the integrity of gonadal germ line and somatic cells. Conditions leading to a loss of genomic integrity are expected to contribute to disease predispositions in offspring

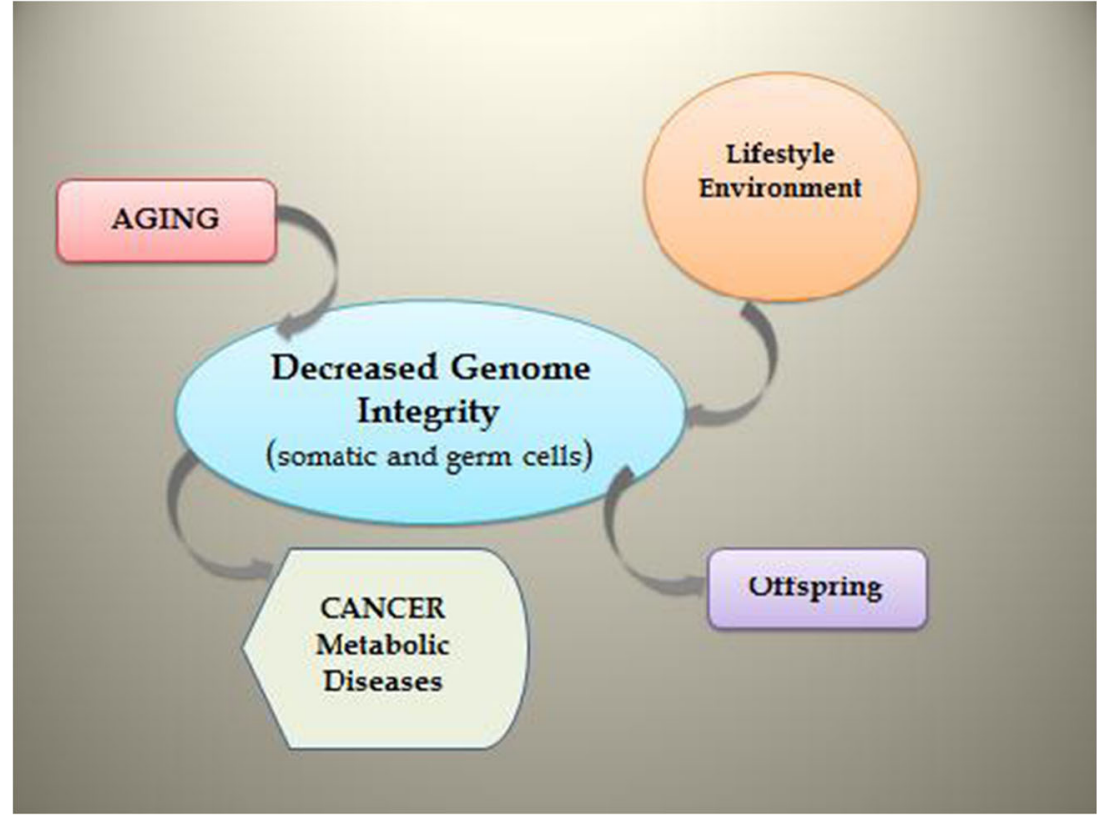

Elsewhere in this paper, the subject of epigenetics will be dealt with in detail but pertinent to the present topic of birth defects are dimensions of nuclear organization that appear to form a foundation for both epigenetics and DNA integrity.

It is now recognized that the architecture of the mammalian nucleus dictates a level of functional organization with regard to chromosome and gene positioning and the disposition of chromatin into what has been classically regarded as heterochromatin or euchromatin. These two conditions are defined as either transcriptionally repressed (heterochromatin) or active (euchromatin); contemporary investigators tend to refer to these as two interdependent states of nuclear organization that are "Closed" or "Open" (Fig. 3).

There is now compelling evidence that during the course of oogenesis and embryogenesis in mammals, transitions between open and closed chromatin states dictate the susceptibility of genomes to undergo epigenetic modifications that involve DNA methylation or histone changes in phosphorylation and methylation, among others.

The status of chromatin is also an important determinant in the ability of cells to recognise and correct DNA damage that occurs as a result of intrinsic oxidative stress [21] or extrinsic sources e.g. lifestyle, aging, or medications. While only recently applied to the study of gametes and embryos [22], there has been solid evidence to support the idea that DNA damage detection and repair mechanisms (DDR) are evident at the RNA level in human eggs and embryos [23]. As there is also mounting evidence to demonstrate that the oocyte can effect a complete DNA damage response (DDR) in both oocytes and resulting embryos [24], including correction of defects harboured in the genome of the fertilizing sperm, the contribution of DDR to the overall genomic integrity of the embryo should be thoroughly investigated as an underlying cause of offspring disease.

\section{Risks related to parental subfertility and its treatment}

Perinatal death, pre-term delivery

Draper et al. [25] assessed the separate contributions to perinatal mortality of subfertility and its treatment in a casecontrol analysis. They calculated an adjusted OR of perinatal mortality of 3.3 (95\%CI 1.6 to 6.8$)$, compared to no

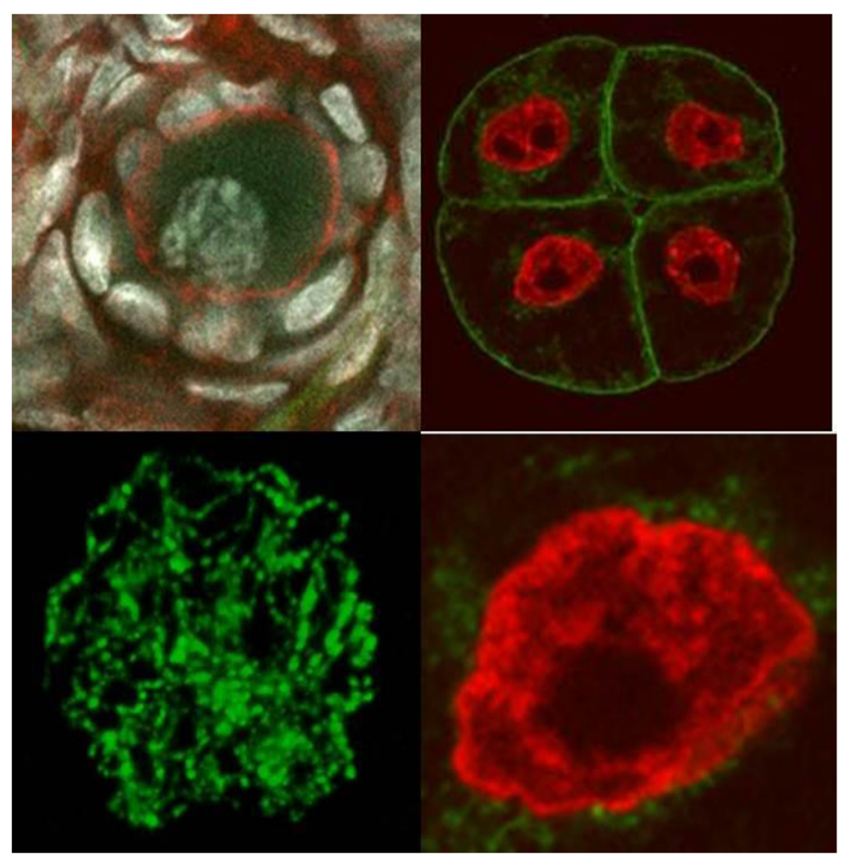

Fig. 3 Chromatin states in human and bovine oocyte nuclei (left) and rat embryo (right) depicting closed (left) or open (right) configurations that in the open state permit ready access of transcription factors ort DNA repair enzymes that would operate less efficiently if chromatin persisted in closed state 
subfertility, for patients spontaneously pregnant after untreated subfertility, and of 2.7 (1.5 to 4.7) for treated subfertility. The authors concluded that babies born after a period of subfertility have a significantly increased risk of perinatal death, irrespective of whether treatment was received or not. Zhu et al. [26], in a Danish national birth cohort study, found the rate of stillbirth to be $0.3 \%$ for fertile couples, $0.4 \%$ for untreated subfertile couples, and $0.5 \%$ for treated subfertile couples $(P=0.01)$.

Henriksen et al. [27] studied preterm delivery after ART. They found that, compared with women who had tried for $<6$ months before they conceived, women who had tried for 7 to 12 months had 1.3 times ( $95 \% \mathrm{CI} 0.8$ to 2.1 ) the adjusted risk of preterm delivery, and women who had tried for $>12$ months had 1.6 (1.1 to 2.2) times that risk [27]. Two other studies $[28,29]$ also concluded that it is the subfertility itself, irrespective of is being treated or not, that is associated with preterm birth.

Messerlian et al. in a systematic review and meta-analysis of 14 eligible studies found that women with a long time to pregnancy (TTP) who conceived without treatment are at an increased risk of preterm birth: pooled crude odds ratio (OR): 1.38 (95 \% CI: $1.25-1.54)$ [30].

In a very elegant retrospective study comparing pregnancies in women who had had at least one spontaneous and one ART pregnancy, Romundstad et al. [31] showed that ART pregnancies do worse than spontaneous pregnancies in the same (subfertile) mother (see later). On a population base, ART pregnancies were associated with lower birth weight ( $25 \mathrm{~g} ; 14$ to $35 \mathrm{~g}$ ), shorter duration ( $2.0 \mathrm{~d}$; 1.6 to $2.3 \mathrm{~d}$ ), and increased risk of small for gestational age (SGA) babies (OR $1.3 ; 1.1$ to 1.4 ) and perinatal mortality (OR $1.3 ; 1.1$ to 1.7 ), compared to spontaneous conceptions. In the sib-sib comparisons however the differences between the spontaneous and the ART conceptions were smaller and no longer significant: birth weight $9 \mathrm{~g} \mathrm{(}-18$ to $36 \mathrm{~g}$ ), gestational age $0.6 \mathrm{~d}$ ( -0.5 to $1.7 \mathrm{~d}$ ). The OR for SGA was 1.0 ( 0.6 to 1.6 ) and for perinatal death $0.4(0.2$ to 0.7$)$, in favour of natural conception.

\section{Congenital malformations}

Children from pregnancies occurring, either spontaneously or induced, after a period of subfertility, are also at higher risk of congenital malformations [32]. Chung et al. [33] found no effect of etiology of subfertility, dose or type of medication used for stimulation, use of embryo-manipulation techniques, or embryo quality on perinatal outcome [33].

In a Dutch registry study, major birth defects in 4224 ART children were compared to 314,605 naturally conceived children [34]. Major birth defect rates were $3.2 \%$ and $2.7 \%$ for ART and naturally conceived children respectively, but the significance of the difference disappeared after adjustment for maternal age, parity and ethnicity. Hansen et al. [35] compared major birth defects in IVF children (8.6\%), ICSI children $(9.0 \%)$ and naturally conceived children $(4.2 \%)$ respectively. The difference between the ART children and the latter group was significant, but the study was criticised since the group of mothers of naturally conceived children was younger, had a higher parity and was of an ethnically more varied composition. In a Danish registry study using singletons born of fertile couples as a reference, singletons born of subfertile couples who conceived naturally [HR 1.2 (1.1 to 1.4)] or after treatment [HR 1.4 (1.2 to 1.6)] had a higher prevalence of congenital malformations; the overall prevalence of congenital malformations increased with increasing time to pregnancy [26]. The authors conclude that "although subfertile couples who conceive naturally may differ from those who seek subfertility treatment in more than care seeking behaviour, they are a more appropriate reference group than fertile couples" (Table 1).

Davies et al. [36] in a study of births and terminations of pregnancy in 308,974 Australian women, followed between 1986 and 2002, showed an increased rate of birth defects associated with intracytoplasmic sperm injection (ICSI) but not with in vitro fertilization (IVF). Furthermore the Authors documented that a history of subfertility by itself raises the birth defects rate.

Hansen et al. [37] compared 92,671 ART children with $3,870,760$ naturally conceived children and found an overall RR for birth defects of 1.32 (95\%CI 1.24 to 1.42 ), and for major birth defects of 1.42 (95\%CI 1.29-1.56). Looking at singletons only the RR was 1.36 (95\%CI $1.30-1.43)$, and at multiples 1.11 (95\%CI 0.98-1.26). For twins with adjustment for zygosity the RR was 1.26 (95\% CI $0.99-1.60)$. The authors conclude that there is an elevated risk of birth defects in children born following ART.

Subfertility is a risk factor for pregnancy complications and birth defects. One has to realise however that subfertile couples, especially those qualifying for ART, are typically older and more often nulliparous than their fertile counterparts [38]. The mechanisms involved in the decreased fertility and increased pregnancy complications are as yet to be identified,

Table 1 Hazard ratios (95\% C.I.) of congenital malformations in singletons conceived either spontaneously or after subfertility treatment according the time to pregnancy [26]

\begin{tabular}{lll}
\hline $\begin{array}{l}\text { Time to } \\
\text { pregnancy } \\
\text { (months) }\end{array}$ & $\begin{array}{l}\text { Conceived } \\
\text { spontaneously } \\
\text { (No. 56.661) }\end{array}$ & $\begin{array}{l}\text { Conceived after } \\
\text { treatment for subfertility } \\
\text { (No. 4.588) }\end{array}$ \\
\hline $0-2$ & 1.00 & - \\
$3-5$ & $1.16(1.06$ to 1.27$)$ & - \\
$6-12$ & $1.17(1.06$ to 1.30$)$ & 1.00 \\
$>12$ & $1.29(1.14$ to 1.45$)$ & $1.34(0.94$ to 1.92$)$ \\
Test for trend* & $p<0.0001$ & $P=0.10$ \\
\hline
\end{tabular}

${ }^{*}$ Cox adjusted regression 
but one explanation for this association might be that an (especially female) exposure first decreases pregnancy chances and then, once conception has occurred, continues to jeopardise the pregnancy and ultimately also the child [39].

One would expect male subfertility factors to play a less important role in problematic pregnancy outcome than female factors. This has not been shown so far [33], however the impact of epigenetic (re) programming during gametogenesis and early embryonic development in either partner of fertile, untreated subfertile and treated subfertile couples still have to be addressed in this respect. Special mention should be made of genital anomalies in boys born after ICSI. It has been shown that deletions of the $\mathrm{Y}$ chromosome are transmitted from father to son [40]. Also the increased incidence of hypospadias in boys born after ICSI has been linked to inherited paternal subfertility factors [35].

\section{Periconceptional parental lifestyle and epigenetic programming of offspring health after spontaneous conception}

During gametogenesis and early embryonic development several biological and lifestyle conditions (age, subfertility, nutrition, smoking, alcohol) can influence the epigenetic fetal programming introducing a number of heritable modifications in gene activity and expression that occur without alteration in DNA sequence [41]. Genomic imprinting operates to silence the maternal or paternal alleles of genes that often are organized in clusters. The gene clusters/genes subjected to genomic imprinting are regulated by a germline differentially methylated region (DMR). In a cluster, genes that are exclusively expressed from the paternal allele can co-exist with genes that are exclusively expressed from the maternal allele. However, the DMR is marked by Cytosine-phosphate-Guanine $(\mathrm{CpG})$ dinucleotide methylation in one of the two germlines. Hence methylation occurs in a sex-specific manner and is maintained throughout fertilization, embryonic and subsequent development [42].

\section{Maternal nutrition}

Low maternal BMI is associated with pregnancy complications such as intrauterine growth retardation and premature delivery [43].

Maternal malnutrition during pregnancy can also predispose offspring to metabolic and cardiovascular diseases in later life. Clinical interest in these latter phenomena originated from the retrospective cohort studies of Barker and Osmond ${ }^{1}$ [44].

\footnotetext{
${ }^{1}$ Anders Forsdahl, an ordinary county doctor in a remote area of Norway first noticed that the frequency of coronary heart disease in different communities correlated to the infant mortality rate and poverty level 40 years earlier $[45,46]$.
}

In one of many studies investigating consequences of prenatal exposure to the Dutch famine in World War II (1944/1945), Painter et al. [47] reported larger babies at birth when mothers were exposed to famine during the first trimester of pregnancy. Furthermore, as adults, this cohort of offspring demonstrated the most striking effects of famine exposure, with a three-fold increase in coronary heart disease, a more extreme atherogenic lipid profile and a higher incidence of obesity relative to offspring of mothers who had not been exposed to famine.

The hypothesis has been advanced that reproductive failure and poor pregnancy outcomes can also arise as a consequence of derangement to metabolic pathways that utilize substrates/ cofactors such as methionine, vitamin B12 and folate [48-50]. Physiologically relevant reductions in specific dietary Bvitamins (i.e. $\mathrm{B}_{12}$, folate) and methionine to intending mothers (sheep) have also been reported to lead to genome-wide.

epigenetic modifications to DNA methylation in their progeny, leading to hypertensive adult offspring that exhibit additional signs of 'metabolic syndrome' including insulin resistance. These effects are most pronounced in male offspring [51].

Recently, the broader effects of disturbances to OneCarbon (1C) metabolism during the periconceptional period from 14 weeks prior to conception to 10 weeks following conception) have been reviewed [52] (Fig. 4).

During this period 'life-style' factors such as diet, body fat mass (i.e. BMI), smoking and alcohol consumption each result in incremental (i.e. 1 to $4 \mu \mathrm{mol} / \mathrm{L}$ ) increases in plasma homocysteine (Hcy) concentrations. The cumulative effect leads to high absolute levels ( $>20 \mu \mathrm{mol} / \mathrm{L}$ ) of Hcy, particularly in individuals with genetic risk alleles.

This frequently associates with poor pregnancy outcomes, including recurrent miscarriages, preeclampsia and congenital abnormalities such as neural-tube defects.

\section{Paternal contribution}

Evidence is emerging from both animal [53] and human [54] studies that paternal diet can also influence offspring development and health. The former study investigated the effects of male rats fed high-fat diets that led to obesity. Their female offspring were glucose intolerant and exhibited impaired insulin secretion. The latter study investigated DNA methylation of two differentially methylated regions (DMRs) within two imprinted genes (i.e. IGF2 and H19) in DNA extracted from cord-blood leucocytes from new-born human infants. In this study hypomethylation of the IGF2 DMR was associated with paternal obesity.

The intrauterine disruption of androgen production

More or less strong associations have been reported between lifestyle factors (e.g. smoking), environmental chemical exposures (e.g. dioxins, certain pesticides) or pharmaceutical usage (paracetamol/acetaminophen) during early pregnancy 


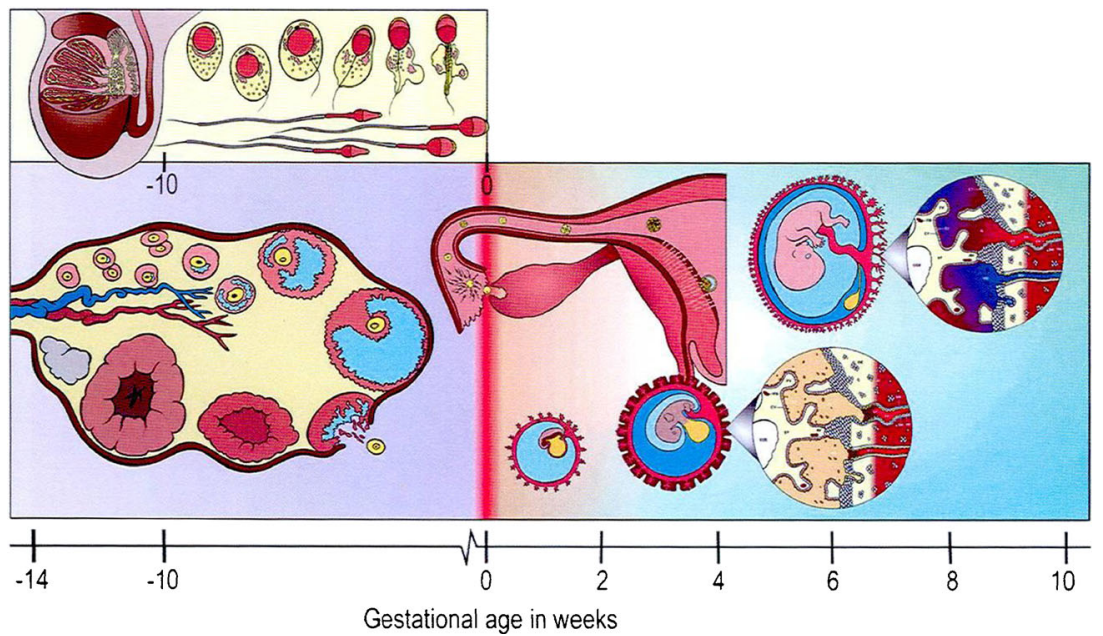

Fig. 4 The periconceptional period in humans* [52]. *Includes five stages. The consecutive processes of spermatogenesis and spermiogenesis in men typically lasts around 10 weeks with final maturation of spermatozoa occurring in the epididymis. In women, primordial ovarian follicles leave their resting state around 26 weeks prior to terminal antral follicle maturation and ovulation, but extensive follicular growth (i.e. primary to late tertiary) commences fromaround 14 weeks preovulation. Following fertilization, hatched blastocysts attach to the endometrial epithelium around Day 6 and the formation of the syncytiotrophoblast

and male reproductive disorders, either evident at birth or in adulthood [55].

Growing evidence suggests that all these disorders are interlinked in terms of their origins [56] and that this probably involves disruption of androgen production or androgen action during a critical 'masculinization programming window (MPW)', which in humans is localised within the period of 8 12 weeks' gestation $[57,58]$.

Any deficiencies in androgen action within the MPW can result in (permanently) reduced adult reproductive organ size and associated abnormalities in structure (e.g. hypospadias) and/or function (eg reduced sperm production) $[58,59]$.

\section{Congenital disorders specifically linked to Art Use}

Hart and Norman $[60,61]$ published recently two back-toback articles on the longer-term health outcomes for children born as a result of IVF treatment; part I is on general health outcomes and part II on mental health and development outcomes. For both articles a search strategy restricted to studies relating to the medical condition of IVF children of at least 1 year of age was used to include case series, data linkage and prospective studies published between 1 January 2000 and 1 April 2012. With regard to general health outcomes, limited long-term follow-up data suggest a possible increase in raised blood pressure, high fasting glucose, increase in total body fat composition, advancement of bone age and subclinical thyroid disorder. It is unclear whether from the embryonic pole is observed from around Day 7 onwards. Implantation of the blastocyst is completed during the second week of embryonic development, although the process of placentation, involving the formation of the villous chorion and decidua basalis, continues for several more weeks. Gastrulation commences during the third week, giving rise to the three germ layers, and leads to the organogenetic period betweenWeeks 4 and 10. At the onset of this period the neural tube forms followed by development of all major organ systems, culminating in the closure of the secondary palate of the embryo by Week 10

these potential associations are related to the IVF therapy, the adverse obstetric outcomes related to IVF or the genetic origin of children. Short-term outcome for children after IVF is positive but other risks later in life need to be addressed by further studies. With regard to mental health and developmental outcomes, limited studies suggest an increase in the incidence of cerebral palsy and neurodevelopmental delay related to confounders of prematurity and low birthweight. Reports of associations with autism and attention-deficit disorder are believed to be related to maternal and obstetric factors. A potential increase in the prevalence of early childhood clinical depression and binge drinking in the offspring of IVF is suggested, but without changes with respect to cognitive development, school performance, social functioning and behavior. Overall mental and emotional health outcome for IVF children are reassuring but further studies are required.

Effects of ART can be brought about by several parts of the ART procedure, two important ones being ovarian hyperstimulation and the resulting alteration of the endocrine environment, and the in vitro development in culture medium after IVF. Both these processes are difficult to investigate in isolation and the in vivo comparison cannot be made [62]. However, not all effects of ovulation induction need to act necessarily via the embryo, another possible mechanism could be reduced endometrial receptivity in stimulated cycles [63].

Imprinting disorders

The incidence of (epi) genetic disorders involving imprinting in humans show a tendency towards an increased risk after 
ART. Eight epidemiologic studies were suitable to calculate the weighted relative risk for the birth of a child with one of these imprinting disorders, the Beckwith-Wiedemann syndrome, following IVF or ICSI compared with the risk in the normal population: RR was 5.2 (95\% CI 1.6-7.4). In only one study was the relative risk corrected for parents' fertility problems and no significant association was found, suggesting that the association lies with a background subfertility effect rather than with ART per se. Data on Silver-Russell syndrome, another imprinting disorder, are too sparse to draw conclusions, and no significant associations have been found between the incidence of either the Angelman or Prader-Willi syndrome and IVF or ICSI treatments. All retinoblastomas in children born after IVF or ICSI could be explained by $C P$ mutations in the RB1 gene and were not associated with imprinted genes [64].

In 2009, it was reported that some genes from babies conceived by means of IVF show a gene expression pattern that differed from naturally conceived children [65]. The authors have stated that this mechanism could put children conceived by means of ART at a greater risk of diseases, such as diabetes and obesity, later in life [65], however follow-up studies are yet to appear.

\section{The role of in vitro embryo nutrition}

Pre-implantation development for the relatively small number of births (i.e. $2-3 \%$ of total births in Europe and North America) established by assisted reproduction (ART) involves short-term exposure of embryos to 'non-physiological' in vitro culture. Hence it is of pivotal importance to consider the effects of periconceptional parental nutrition and culture media composition on offspring health (Fig. 4).

IVF children derived from embryos that were cultured randomly in one of two different media showed a significant difference in placental weight [66] and in birth weight [67], although other studies have failed to confirm this difference [62].

Human term pregnancies following ART are associated with small for gestational age (SGA) babies, although a recent retrospective cross sectional cohort study from Finland, involving extended culture to the blastocyst stage, reported the incidence of large for gestational age (LGA) babies to be twice that of the national register and six-fold greater than the incidence of SGA [68].

Recent work with bovine embryos has revealed that in these large babies the gene, most misregulated in BeckwithWiedemann Syndrome, is bi-allelically expressed in LGA conceptuses and is associated with a loss of methylation at the KvDMR1 locus on the maternal allele [69].

The continuing trend towards extended culture in human ART may increase the incidence of LGA babies and associated complications in the future.
More research needs to be performed to analyse the effects of individual culture medium formulations and to evaluate the long-term effects of embryo culture medium on the health of children conceived through ART [70, 71].

\section{Preimplantation screening}

Preimplantation genetic screening (PGS) has been a hotly debated topic ever since its introduction into the ART clinic. Studies in favour [72, 73] and against [74] have been published, but they also have been criticized because of including only good prognosis patients (not the clinical target group), skewed randomisation and low aneuploidy rates increasing the negative predictive value. There exist only few high quality studies. A recent randomised trial [73] showed a significant increase of live birth rates after the screening of chromosome abnormalities in single-cell day 3 biopsies for advanced maternal age: $32.3 \%$ vs $15.5 \%$ (OR $2.695 \%$ CI $1.3-5.3$ ). Similarly, an improved performance was observed in young women (mean age 32 years) in an RCT with chromosome screening on blastocyst biopsies [72], where the incidence of sustained implantation rates was significantly higher in the screened group (66.4\%) compared with the controls (47.9\%). The authors prudently conclude that "future studies and broad based clinical application will be required to fully define the role of aneuploidy screening" [72]. New genetic laboratory techniques for preimplantation genetic screening deserve to be tested in the same rigorous way as the older (PCR, FISH) ones. The results so far suggest that a consistent proportion of aneuploid embryos arrest their growth at some stage of development, even after blastocyst formation [75].

\section{The ART "Nordic studies"}

\section{The ART registries}

In the Nordic countries, all citizens are assigned a personal identification number at birth. This number identifies the individual in all public registries including hospital, disease, birth and death registries and registries of socioeconomic factors such as education, occupation, income and marital status. Information in these records may be coupled through the personal identification number. In each of the Nordic countries there is a nation-wide registry of all pregnancies from ART. This registry may be linked to the medical birth registry for information about the pregnancy, delivery and neonatal period, to the cancer registry for data on cancer incidence, to the hospital discharge registry for more general information about the health of the child. Since these registries are nation-wide, the whole population serves as the control group and also makes it easier to control for confounding 
Table 2 Norvegian data on ART conceived children and their siblings

\begin{tabular}{llllll}
\hline $\begin{array}{l}\text { Parameter } \\
\text { studied }\end{array}$ & $\begin{array}{l}\text { Total number of singleton } \\
\text { deliveries in the reference } \\
\text { population }\end{array}$ & $\begin{array}{l}\text { Singleton } \\
\text { deliveries after } \\
\text { ART }\end{array}$ & $\begin{array}{l}\text { Pairs of } \\
\text { singleton } \\
\text { siblings * }\end{array}$ & $\begin{array}{l}\text { ART-singletons Adjusted } \\
\text { odds ratio, reference } \\
\text { population }\end{array}$ & $\begin{array}{l}\text { ART-singletons Adjusted odds } \\
\text { ratio compared to sibling born } \\
\text { after spontaneous conception }\end{array}$ \\
\hline Placenta praevia & $882040^{* *}$ & 5,581 & 1,349 & $5,6(4,4-7,0)$ & $2,9(1,4-6,1)$ \\
Delivery <37 weeks & $1127739^{* * *}$ & 7,474 & 2,204 & $1,69(1-55-1,85)$ & $1,20(0,9-1,61)$ \\
Small for gestational age & $11,27739^{* * *}$ & 7,474 & 2,204 & $1,26(1,10-1,44)$ & $0,99(0,62-1,57)$ \\
Perinatal death & $1200922^{* * *}$ & 8,229 & 2,546 & $1,31(1,05-1,65)$ & $0,36(0,2-0,67)$ \\
\hline
\end{tabular}

* One singleton from ART, and one from spontaneous conception

$* *[83] * * *[31]$

factors in the study group. It is also possible to link the ART registry to information about parents, grandparents and siblings in an attempt to disentangle the effect of ART from genetic and socioeconomic confounders. Recently the data in some Nordic registries were combined into large megaregistries. The population-base of these registries is over 25 million and the ART registry contains information about nearly 90,000 children [76]. The registries are updated regularly. Data from more than 300,000 deliveries, including more than 12,000 children born after ART, are annually added to the Nordic ART-registry.

Norwegian data on ART children and their siblings

In the Norwegian medical birth registry, looking at couples who had two singletons, one from ART and one from spontaneous conception the parental effects on children born may be separated by the effects of ART (Table 2).

In table 3, only data for which the ART population is seemingly different to the reference population are shown.

ART singletons are born earlier and are smaller for gestational age (SGA) compared to spontaneously conceived children from the same mother. SGA is associated with increased risk for cardiovascular disorders later in life.

Table 3 Future health risks: differences between reference and ART population

\begin{tabular}{llll}
\hline Parameter studied & $\begin{array}{l}\text { Total number } \\
\text { of children } \\
\text { in the study } \\
\text { population }\end{array}$ & $\begin{array}{l}\text { Total number } \\
\text { of ART children } \\
\text { in the study } \\
\text { population }\end{array}$ & $\begin{array}{l}\text { ART children } \\
\text { adjusted odds } \\
\text { ratio }\end{array}$ \\
\hline $\begin{array}{l}\text { Convulsions* } \\
\text { Upper respiratory } \\
\text { tract infection* }\end{array}$ & 29367 & 277 & $1,28(1,14-1,78)$ \\
$\begin{array}{l}\text { Accidents* } \\
\text { Fracture* }\end{array}$ & 200234 & 1345 & $1,15(1,06-1,25)$ \\
Childhood cancer** & 50957 & 170 & $1,29(1,21-1,36)$ \\
\hline
\end{tabular}

* Data only from children born at term [84], **[85]
Studies of siblings where one child is from ART and the other from spontaneous conception, as well as populationwide studies, suggest that low birth weight has a strong link to both maternal and paternal factors [31, 77].

Generally the data are ressuring, nevertheless a small but consistent increase in blood pressure of ART-children compared to children born after spontaneous conceptions has been found $[78,79]$. This in contrast to a recent study from Belgium that failed to confirm the difference in ICSI children [80].

Scherrer et al. [81] did a more detailed analysis of cardiovascular parameters in singletons born after uneventful pregnancies following ART or spontaneous conception, and found a raised pulmonary blood pressure registered only at higher altitude in children born after ART [81].

A more detailed analysis of vascular dynamics revealed that flow mediated dilation, pulse-wave velocity and carotid intima-thickness were different in ART-children. The authors conclude that ART children display generalized vascular dysfunction and that these are related to the ARTprocedure $[79,82]$.

\section{International registry of ART babies}

Children's health after all forms of assisted reproduction remains the most critical question to be answered even 35 years after the birth of Louise Brown. ART has brought a child to literally hundreds of thousands of couples who would otherwise not have conceived; it is now estimated that up to $4 \%$ of all births in developed nations involve ART [32]. The oldest ART offspring are entering adult life. Outcomes at birth are important but follow-up needs to be continued later on in life. Not only outcome after conventional IVF or ICSI needs to be assessed but other "treatment" options need also to be assessed including ovulation induction, so-called 'controlled' ovarian stimulation, and intrauterine insemination. The different treatment strategies need to be compared to each other but also to spontaneous conceptions in fertile and subfertile couples. 
Two types of studies may answer the key questions on safety, efficacy, access, quality and cost: national and international registries as well as defined research follow-up studies. Pitfalls in registration involve the definitions, observation bias, the selection of an appropriate control group and loss to follow-up rate as well as the sample size. Caution is required because anomalies in ART may be overreported (observation bias for congenital anomalies) or under-reported if not recognized (e.g. minor expression of imprinting disorders). Cross-linking registries may elicit ethical concerns and the understanding of mechanisms involved is limited. Specific disease registers (imprinting disorders, cancer) have no bias for ART, but data on ART is sometimes missing; data need to be linked to existing ART registers.

\section{Conclusion}

Babies born after assisted reproduction differ from neonates born from pregnancies originating from natural conception. They are born earlier, smaller and as a group tend to exhibit a small increase in birth defects. Assisted reproduction however is here to stay. It allows many previously subfertile and infertile ('sterile') couples to have a child (or children) of their own. We should however not close our eyes for the increase in birth defects, especially now that the indications for assisted reproduction seem to be getting less and less strict. The wide divergence in application of IVF related techniques between European countries alone, and the fact that even large scale studies can be published nowadays about women having siblings by both natural and assisted conception, should raise awareness. In each European school class room there is now at least one ART child, but this should not lead to the conclusion that they would not have been there without ART. Gradually the positive and negative effects of ART are becoming clearer. The increase in birth defects is one such negative aspect. An important confounder in many observational studies however is the parental background. Subfertility as such and type of subfertility turn out to be important independent determinants of ART outcome. Hence, for each clinical question addressed in a particular study, the appropriate controls have to be selected. Sometimes national registry figures will suffice; in other circumstances untreated or treated subfertile controls are more appropriate. An important issue of future concern is the long-term developmental effects of ART on child and adult health and disease, irrespective of whether any changes result from ART itself, the underlying subfertility or the fact that ART babies tend to be born earlier and smaller. A better understanding of the risks and causal factors may enable better treatments of subfertile couples and improve management of the resulting offspring.
Acknowledgments The secretarial assistance of Mrs Simonetta Vassallo is gratefully acknowledged.

Funding statement The meeting was organized by the European Society of Human Reproduction and Embryology with an unrestricted educational grant from Institut Biochimique S.A. (Switzerland).

\section{References}

1. Harvey W. Exercitationes de Generatione Animalium. Londinii 1651.

2. Wilson EB. The Cell in Development and Heredity: Macmillan, New York; 1925

3. Raven Chr. P. Oogenesis: the storage of developmental information. Pergamon Press, The Macmillan Company, New York. 1961.

4. Hammond TC, Lecture M. Are follicular maturation and oocyte maturation independent processes? J Reprod Fertil. 1977;51:1-15.

5. Hutt KJ, Albertini DF. An oocentric view of folliculogenesis and embryogenesis. Reprod Biomed Online. 2007;14:758-64.

6. Hutt KJ, Shi Z, Albertini DF, Petroff BK. The environmental toxicant 2,3,7,8-tetrachlorodibenzo-p-dioxin disrupts morphogenesis of the rat pre-implantation embryo. BMC Dev Biol. 2008;8:1.

7. Ménézo Y, Dale B, Cohen M. DNA damage and repair in human oocytes and embryos: a review. Zygote. 2010;18:357-65.

8. Surén P, Roth C, Bresnahan M, Haugen M, Hornig M, Hirtz $\mathrm{D}$, et al. Association between maternal use of folic acid supplements and risk of autism spectrum disorders in children. JAMA. 2013;309:570-7.

9. Ménézo Y, Mares P, Cohen M, Brack M, Viville S, Elder K. Autism, imprinting and epigenetic disorders: a metabolic syndrome linked to anomalies in homocysteine recycling starting in early life?? J Assist Reprod Genet. 2011;28:1143-5.

10. Hutt KJ, Shi Z, Petroff BK, Albertini DF. The environmental toxicant 2,3,7,8-tetrachlorodibenzo-p-dioxin disturbs the establishment and maintenance of cell polarity in preimplantation rat embryos. Biol Reprod. 2010;82:914-20.

11. Abbott DH, Bacha F. Ontogeny of polycystic ovary syndrome and insulin resistance in utero and early childhood. Fertil Steril. 2013;100: $2-11$.

12. Bromfield J, Messamore W, Albertini DF. Epigenetic regulation during mammalian oogenesis. Reprod Fertil Dev. 2008;20:74-80.

13. Peng H, Chang B, Lu C, Su J, Wu Y, Lv P, et al. Nlrp2, a maternal effect gene required for early embryonic development in the mouse. PLoS One. 2012;7:e30344.

14. McGinnis LK, Limback SD, Albertini DF. Signaling modalities during oogenesis in mammals. Curr Top Dev Biol. 2013;102:22742 .

15. Gougeon A. Ovarian follicular growth in humans: ovarian ageing and population of growing follicles. Maturitas. 1998;30:137-42.

16. Nagaoka SI, Hassold TJ, Hunt PA. Human aneuploidy: mechanisms and new insights into an age-old problem. Nat Rev Genet. 2012;13: 493-504.

17. Wang RH, Sengupta K, Li C, Kim HS, Cao L, Xiao C, et al. Impaired DNA damage response, genome instability, and tumorigenesis in SIRT1 mutant mice. Cancer Cell. 2008;14:312-23.

18. Nagaoka SI, Hodges CA, Albertini DF, Hunt PA. Oocyte-specific differences in cell-cycle control create an innate susceptibility to meiotic errors. Curr Biol. 2011;21:651-7.

19. Duesberg P, Stindl R, Hehlmann R. Explaining the high mutation rates of cancer cells to drug and multidrug resistance by chromosome reassortments that are catalyzed by aneuploidy. Proc Natl Acad Sci U S A. 2000;97:14295-300. 
20. Duncan FE, Hornick JE, Lampson MA, Schultz RM, Shea LD, Woodruff TK. Chromosome cohesion decreases in human eggs with advanced maternal age. Aging Cell. 2012;11:1121-4.

21. Gowen LC, Avrutskaya AV, Latour AM, Koller BH, Leadon SA. BRCA1 required for transcription-coupled repair of oxidative DNA damage. Science. 1998;281:1009-12.

22. Di Giacomo M, Barchi M, Baudat F, Edelmann W, Keeney S, Jasin M. Distinct DNA-damage-dependent and -independent responses drive the loss of oocytes in recombination-defective mouse mutants. Proc Natl Acad Sci U S A. 2005;102:737-42.

23. Ménézo Jr Y, Russo G, Tosti E, El Mouatassim S, Benkhalifa M. Expression profile of genes coding for DNA repair in human oocytes using pangenomic microarrays, with a special focus on ROS linked decays. J Assist Reprod Genet. 2007;24:513-20.

24. Carroll J, Marangos P. The DNA damage response in mammalian oocytes. Front Genet. 2013;4:117.

25. Draper ES, Kurinczuk JJ, Abrams KR, Clarke M. Assessment of separate contributions to perinatal mortality of infertility history and treatment: a case-control analysis. Lancet. 1999;353:1746-9.

26. Zhu JL, Basso O, Obel C, Bille C, Olsen J. Infertility, infertility treatment, and congenital malformations: Danish national birth cohort. BMJ. 2006;333:679-84.

27. Henriksen TB, Baird DD, Olsen J, Hedegaard M, Secher NJ, Wilcox AJ. Time to pregnancy and preterm delivery. Obstet Gynecol. 1997;89:594-9.

28. Bhalla AK, Sarala G, Dhaliwal L. Pregnancy following infertility. Aust N Z J Obstet Gynaecol. 1992;32:249-51.

29. Joffe M, Li Z. Association of time to pregnancy and the outcome of pregnancy. Fertil Steril. 1994;62:71-5.

30. Messerlian C, Maclagan L, Basso O. Infertility and the risk of adverse pregnancy outcomes: a systematic review and meta-analysis. Hum Reprod. 2013;28:125-37.

31. Romundstad LB, Romundstad PR, Sunde A, von During V, Skjaerven R, Gunnel D, et al. Effects of technology or maternal factors on perinatal outcome of assisted reproduction: a populationbased cochort study. Lancet. 2008;372:737-43.

32. Sutcliffe A, Ludwig M. Outcome of assisted reproduction. Lancet. 2007;370:351-9.

33. Chung K, Coutifaris C, Chalian R, Lin K, Ratcliffe SJ, Castelbaum $\mathrm{AJ}$, et al. Factors influencing adverse perinatal outcomes in pregnancies achieved through use of in vitro fertilization. Fertil Steril. 2006;86:1634-41.

34. Anthony S, Buitendijk SE, Dorrepaal CA, Lindner K, Braat DD, den Ouden AL. Congenital malformations in 4224 children conceived after IVF. Hum Reprod. 2002;17:2089-95.

35. Hansen M, Kurinczuk JJ, Bower C, Webb S. The risk of major birth defects after intracytoplasmic sperm injection and in vitro fertilization. N Engl J Med. 2002;346:725-30.

36. Davies MJ, Moore VM, Willson KJ, Van Essen P, Priest K, Scott H, et al. Reproductive technologies and the risk of birth defects. N Engl J Med. 2012;366:1803-13.

37. Hansen M, Kurinckzuk JJ, Milne E, de Klerk N, Bower C. Assisted reproductive technology and birth defects: a systematic review and meta-analysis. Hum Reprod Update. 2013;19:330-53.

38. De Graaff AA, Land JA, Kessels AG, Evers JL. Demographic age shift toward later conception results in an increased age in the subfertile population and an increased demand for medical care. Fertil Steril. 2011;95:61-3.

39. Baird DD, Wilcox AJ, Kramer MS. Why might infertile couples have problem pregnancies? Lancet. 1999;353:1724-5.

40. Mau Kai C, Juul A, McElreavey K, Ottesen AM, Garn ID, Main KM, et al. Sons conceived by assisted reproduction techniques inherit deletions in the azoospermia factor (AZF) region of the $\mathrm{Y}$ chromosome and the DAZ gene copy number. Hum Reprod. 2008;23:1669-78.

41. Goldberg AD, Allis CD, Bernstein E. Epigenetics: a landscape takes shape. Cell. 2007;128:635-8.
42. Reik W, Walter J. Genomic imprinting: parental influence on the genome. Nat Rev Genet. 2001;2:21-32.

43. ESHRE Capri Workshop Group. Nutrition and reproduction in women. Hum Reprod Update. 2006;12:193-207.

44. Barker DJ, Osmond C. Low birth weight and hypertension. BMJ. 1988;297:134-5.

45. Forsdahl A. Are poor living conditions in childhood and adolescence an important risk factor for arteriosclerotic heart disease. J Prevent Soc Med. 1977;31:91-5.

46. Forsdahl A. Living conditions in childhood and subsequent development of risk factors for arteriosclerotic heart disease. J Epidemiol Commun Health. 1978;32:34-7.

47. Painter RC, Roseboom TJ, Bleker OP. Prenatal exposure to the dutch famine and disease in later life: an overview. Reprod Toxicol. 2005;20:345-52.

48. Lucock M. Folic acid: nutritional biochemistry, molecular biology, and role in disease processes. Mol Genet Metab. 2000;71:121-38.

49. Refsum H, Nurk E, Smith AD, Ueland PM, Gjesdal CG, Bjelland I, et al. The hordaland homocysteine study: a community-based study of homocysteine, its determinants, and associations with disease. J Nutr. 2006;136(6 Suppl):1731S-40S.

50. Rush EC, Katre P, Yajnik CS. Vitamin B12: one carbon metabolism, fetal growth and programming of chronic disease. Eur J Clin Nutr. 2014;68:2-7.

51. Sinclair KD, Allegrucci C, Singh R, Gardner DS, Sebastian S, Bispham J, et al. DNA methylation, insulin resistance, and blood pressure in offspring determined by maternal periconceptional $\mathrm{B}$ vitamin and methionine status. Proc Natl Acad Sci U S A. 2007;104:19351-6.

52. Steegers-Theunissen RPM, Twigt J, Pestinger V, Sinclair KD. The periconceptional period, reproduction and long-term health of offspring: the importance of one-carbon metabolism. Hum Reprod Update. 2013;19:640-55.

53. Ng SF, Lin RC, Laybutt DR, Barres R, Owens JA, Morris MJ. Chronic high-fat diet in fathers programs $\beta$-cell dysfunction in female rat offspring. Nature. 2010;467:963-6.

54. Soubry A, Schildkraut JM, Murtha A, Wang F, Huang Z, Bernal A, et al. Paternal obesity is associated with IGF2 hypomethylation in newborns: results from a Newborn Epigenetics Study (NEST) cohort. BMC Med. 2013;11:29.

55. Sharpe RM. Environmental/lifestyle effects on spermatogenesis. Philos Trans R Soc Lond B Biol Sci. 2010;365:1697-712.

56. Sharpe RM, Skakkebaek NE. Testicular dysgenesis syndrome: mechanistic insights and potential new downstream effects. Fertil Steril. 2008;89 Suppl 1:e33-8.

57. Welsh M, Saunders PTK, Fisken M, Scott HM, Hutchison GR, Smith $\mathrm{LB}$, et al. Identification in rats of a programming window for reproductive tract masculinization, disruption of which leads to hypospadias and cryptorchidism. J Clin Invest. 2008;118:1479-90.

58. Dean A, Sharpe RM. Anogenital distance or digit length ratio as measures of fetal androgen exposure: relationship to male reproductive development and its disorders. J Clin Endocrinol Metab. 2013;98:2230-8.

59. Drake AJ, Van den Driesche S, Scott HM, Hutchison G, Seckl JR, Sharpe RM. Glucocorticoids amplify dibutyl phthalate-induced disruption of fetal testosterone production and male reproductive development. Endocrinology. 2009;150:5055-64.

60. Hart R, Norman RJ. The longer-term health outcomes for children born as a result of IVF treatment: part I - general health outcomes. Hum Reprod Update. 2013;19:232-43.

61. Hart R, Norman RJ. The longer-term health outcomes for children born as a result of IVF treatment. Part II - mental health and development outcomes. Hum Reprod Update. 2013;19:244-50.

62. van Montfoort AP, Hanssen LL, de Sutter P, Viville S, Geraedts JP, de Boer P. Assisted reproduction treatment and epigenetic inheritance. Hum Reprod Update. 2012;18:171-97. 
63. Haouzi D, Assou S, Dechanet C, Anahory T, Dechaud H, De Vos J, et al. Controlled ovarian hyperstimulation for in vitro fertilization alters endometrial receptivity in humans: protocol effects. Biol Reprod. 2010;82:679-86.

64. Vermeiden JP, Bernardus RE. Are imprinting disorders more prevalent after human in vitro fertilization or intracytoplasmic sperm injection? Fertil Steril. 2013;99:642-51.

65. Katari S, Turan N, Bibikova M, Erinle O, Chalian R, Foster M, et al. DNA methylation and gene expression differences in children conceived in vitro or in vivo. Hum Mol Genet. 2009;18:3769-78.

66. Eskild A, Monkerud L, Tanbo T. Birthweight and placental weight; do changes in culture media used for IVF matter? Comparisons with spontaneous pregnancies in the corresponding time periods. Hum Reprod. 2013;28:3207-14.

67. Dumoulin JC, Land JA, Van Montfoort AP, Nelissen EC, Coonen E, Derhaag JG, et al. Effect of in vitro culture of human embryos on birthweight of newborns. Hum Reprod. 2010;25:605-12.

68. Mäkinen S, Söderström-Anttila V, Vainio J, Suikkari AM, Tuuri T. Does long in vitro culture promote large for gestational age babies? Hum Reprod. 2013;28:828-34.

69. Chen Z, Robbins KM, Wells KD, Rivera RM. Large offspring syndrome: a bovine model for the human loss-of-imprinting overgrowth syndrome beckwith-wiedemann. Epigenetics. 2013;8:591601.

70. Lin S, Li M, Lian Y, Chen L, Liu P. No effect of embryo culture media on birthweight and length of newborns. Hum Reprod. 2013;28:1762-7.

71. Carrasco B, Boada M, Rodríguez I, Coroleu B, Barri PN, Veiga A. Does culture medium influence offspring birth weight? Fertil Steril. 2013;100:1283-8.

72. Scott Jr RT, Upham KM, Forman EJ, Hong KH, Scott KL, Taylor D, et al. Blastocyst biopsy with comprehensive chromosome screening and fresh embryo transfer significantly increases in vitro fertilization implantation and delivery rates: a randomized controlled trial. Fertil Steril. 2013;100:697-703.

73. Rubio C, Bellver J, Rodrigo L, Bosch E, Mercader A, Vidal C, et al. Preimplantation genetic screening using fluorescence in situ hybridization in patients with repetitive implantation failure and advanced maternal age: two randomized trials. Fertil Steril. 2013;99:1400-7.

74. Mastenbroek S, Twisk M, van Echten-Arends J, Sikkema-Raddatz B, Korevaar JC, Verhoeve HR, et al. In vitro fertilization with preimplantation genetic screening. N Engl J Med. 2007;357:9-17.
75. Alfarawati S, Fragouli E, Colls P, Stevens J, Gutiérrez-Mateo C, Schoolcraft WB, et al. The relationship between blastocyst morphology, chromosomal abnormality, and embryo gender. Fertil Steril. 2011;95:520-4.

76. Henningsen AK, Romundstad LB, Gissler M, Nygren KG, Lidegaard $\mathrm{O}$, Skjaerven R, et al. Infant and maternal health monitoring using a combined Nordic database on ART and safety. Acta Obstet Gyn Scand. 2011;90:683-91.

77. Myklestad K, Vatten LJ, Magnussen EB, Salvesen KA, Smith GD, Romundstad PR. Offspring birth weight and cardiovascular risk in parents: a population-based HUNT 2 study. Am J Epidemiol. 2012;175:546-55.

78. Ceelen M, van Weissenbruch MM, Vermeiden JP, van Leeuwen FE, de Waal HA D-v. Cardiometabolic differences in children born after in vitro fertilization: follow-up study. J Clin Endocrinol Metab. 2008;93:1682-8.

79. Ceelen M, van Weissenbruch MM, Prein J, Smit JJ, Vermeiden JP, Spreeuwenberg M, et al. Delemarre-van de Waal HA. Growth during infancy and early childhood in relation to blood pressure and body fat measures at age 8-18 years of IVF children and spontaneously conceived controls born to subfertile parents. Hum Reprod. 2009;24:2788-95.

80. Belva F, Roelants M, De Schepper J, Roseboom TJ, Bonduelle M, Devroey P, et al. Blood pressure in ICSI-conceived adolescents. Hum Reprod. 2012;27:3100-8.

81. Scherrer U, Rimoldi SF, Rexhaj E, Stuber T, Duplain H, Garcin S, et al. Systemic and pulmonary vascular dysfunction in children conceived by assisted reproductive technologies. Circulation. 2012;125:1890-6.

82. Ceelen M, van Weissenbruch MM, Roos JC, Vermeiden JP, van Leeuwen FE, de Waal HA D-v. Body composition in children and adolescents born after in vitro fertilization or spontaneous conception. J Clin Endocrinol Metab. 2007;92:3417-23.

83. Romundstad LB, Romundstad PR, Sunde A, von During V, Skjaerven R, Vatten LJ. Increased risk of placenta previa in pregnancies following IVF/ICSI; a comparison of ART and non-ART pregnancies in the same mother. Hum Reprod. 2006;21:2353-8.

84. Kallen B, Finnstrom O, Nygren KG, Olausson PO. In vitro fertilization in Sweden: child morbidity including cancer risk. Fertil Steril. 2005;84:605-10.

85. Kallen B, Finnstrom O, Lindam A, Nilsson E, Nygren KG, Olausson PO. Cancer risk in children and young adults conceived by in vitro fertilization. Pediatrics. 2010;126:270-6. 